\title{
CAPÍTULO 09: ACESSIBILIDADE NO TURISMO: UMA PROPOSTA DE INCLUSÃO DE ROTEIROS ACESSÍVEIS NO CALENDÁRIO DE EXCURSÕES DAS AGÊNCIAS DE TURISMO SOCIAL DO SESC - PE
}

\author{
CAPÍTULO 09: ACCESIBILIDAD EN TURISMO: UNA PROPUESTA PARA LA \\ INCLUSIÓN DE TOURS ACCESIBLES EN EL CALENDARIO DE EXCURSIONES \\ DE AGENCIAS DE TURISMO SOCIAL EN SESC - PE
}

\author{
CHAPTER 09: ACCESSIBILITY IN TOURISM: A PROPOSAL FOR THE \\ INCLUSION OF ACCESSIBLE TOURS IN THE EXCURSIONS CALENDAR OF \\ SOCIAL TOURISM AGENCIES IN SESC - PE
}

\begin{abstract}
Rosangela Rodrigues Lima dos Santos ${ }^{1}$; Bruna de Barros Soares ${ }^{2}$; Lizandra Silva Bezerra ${ }^{3}$; Derek Luiz Alves dos Santos ${ }^{4}$; Simone de Paula Silva ${ }^{5}$
\end{abstract}

DOI: $\underline{\text { https://doi.org/10.31692/978-65-88970-03-4.140-155 }}$

\section{RESUMO}

No Serviço Social do Comércio, a prestação de serviços turísticos ocorre por meio das agências de Turismo Social. Mesmo a instituição abordando a questão da acessibilidade em diversos momentos (principalmente em congressos e palestras), a criação de um roteiro turístico acessível até então não foi uma iniciativa contemplada, apesar do potencial de crescimento social e de bem-estar comunitário. Este trabalho objetiva sugerir uma proposta de inclusão de roteiros turísticos acessíveis a pessoas com necessidades específicas nas agências de Turismo Social do SESC/PE, por meio do planejamento de um roteiro acessível a deficientes auditivos para a agência de Turismo Social da unidade do bairro de Santo Amaro em Recife/PE. Trata-se de um relato de experiência. Na referida perspectiva, propõe-se uma pesquisa de natureza aplicada, com abordagem quali-quanti. Possui um enfoque exploratóriodescritivo, tendo como procedimentos de pesquisa o tipo estudo de caso. A coleta de dados e informações se deu por levantamento documental e de bibliografia. Por meio da análise, percebeu-se que o não uso da Língua Brasileira de Sinais - LIBRAS no provimento de serviços turísticos é a principal causa pela qual há o receio por parte das pessoas surdas em viajar. Nas agências de Turismo Social do SESC/PE (como em toda agência de turismo) há um molde previamente estabelecido quando se trata da elaboração de roteiros turísticos e sua comercialização, excluem-se, entretanto, as particularidades que estão ligadas ao público-alvo concernente a segmentação turística e atrativos a serem utilizados. Diante da realidade encontrada no Brasil, é observado que há uma necessidade na melhora da acessibilidade dos serviços e equipamentos turísticos. Para os deficientes auditivos, essa acessibilidade ocorre através da quebra da barreira da comunicação que se dá pelo uso da LIBRAS. Ao propor a criação de um pacote turístico inclusivo nesse aspecto, as agências de turismo podem atuar no processo da inclusão social da pessoa com deficiência, auxiliando na melhora das condições de acesso dos atrativos e no progresso do mercado turístico nesse aspecto. É de extrema importância que esses tipos de iniciativas sejam perpetuados, não só pelas agências de Turismo SESC/PE, mas por todo o trade (mercado).

Palavras-chave: Turismo social, Turismo acessível, Libras.

\section{RESUMEN}

En el Servicio Social de Comercio, los servicios turísticos se brindan a través de agencias de Turismo Social. Si bien la institución abordó el tema de la accesibilidad en diferentes

\footnotetext{
${ }^{1}$ Graduanda em Gestão de Turismo, Instituto Federal de Pernambuco - IFPE, rrls@discente.ifp

${ }^{2}$ Graduada, Instituto Federal de Pernambuco - IFPE, brunasoarescontato@hotmail.com

${ }^{3}$ Graduada, Serviço Social do Comércio Pernambuco - SESC/PE, 1sbezerra@sescpe.co

${ }^{4}$ Mestre, Instituto Federal de Pernambuco - IFPE, derek.alves@recife.ifpe.edu.br

${ }^{5}$ Mestre, Instituto Federal de Pernambuco - IFPE, simonedypaula@gmail.com
} 
(principalmente en congresos y conferencias), la creación de un itinerario turístico accesible hasta ese momento no era una iniciativa contemplada, a pesar del potencial de crecimiento social y bienestar comunitario. Este trabajo tiene como objetivo sugerir una propuesta para la inclusión de itinerarios turísticos accesibles a personas con necesidades específicas en las agencias de Turismo Social de SESC / PE, a través de la planificación de un guión accesible para personas con discapacidad auditiva para la agencia de Turismo Social de la unidad vecinales Santo Amaro. en Recife / PE. Es un relato de experiencia. En esta perspectiva, se propone una investigación de carácter aplicado, con un enfoque cuantitativo y cualitativo. Tiene un enfoque exploratorio-descriptivo, con procedimientos de investigación como estudio de caso. La recolección de datos e información se realizó a través de un relevamiento documental y bibliográfico. A través del análisis, se constató que la no utilización de la Lengua de Signos Brasileña - LIBRAS en la prestación de servicios turísticos es la principal causa por la cual existe el temor de las personas sordas a viajar. En las agencias de Turismo Social SESC / PE (como en cualquier agencia de turismo) existe un molde previamente establecido a la hora de la elaboración de itinerarios turísticos y su comercialización, sin embargo, se excluyen las particularidades que se vinculan al público objetivo. la segmentación turística y los atractivos a utilizar. En vista de la realidad encontrada en Brasil, se observa que existe la necesidad de mejorar la accesibilidad de los servicios y equipamientos turísticos. Para las personas con discapacidad auditiva, esta accesibilidad se produce al romper la barrera de comunicación que se produce mediante el uso de la Lengua de Señas Brasileña - LIBRAS. Al proponer la creación de un paquete turístico inclusivo en este sentido, las agencias de turismo pueden actuar en el proceso de inclusión social de las personas con discapacidad, contribuyendo a mejorar las condiciones de acceso a los atractivos, y en el avance del mercado turístico en este sentido. Es sumamente importante que este tipo de iniciativas sean perpetuadas, no solo por las agencias de turismo SESC / PE, sino en todo el comercio.

Palabras clave: Turismo social, Turismo accesible, Libras.

\section{ABSTRACT}

In the Social Service of Commerce, tourist services are provided through Social Tourism agencies. Even though the institution addressed the issue of accessibility at different times (mainly at congresses and lectures), the creation of an accessible tourist itinerary until then was not an initiative contemplated, despite the potential for social growth and community well-being. This work aims to suggest a proposal for the inclusion of tourist itineraries accessible to people with specific needs in the Social Tourism agencies of SESC / PE, through the planning of a script accessible to the hearing impaired for the Social Tourism agency of the Santo Amaro neighborhood unit. in Recife / PE. It is an experience report. In this perspective, research of an applied nature is proposed, with a quantitative and qualitative approach. It has an exploratory-descriptive approach, with research procedures as the case study. The collection of data and information took place through a documentary and bibliographic survey. Through the analysis, it was realized that the non-use of the Brazilian Sign Language LIBRAS in the provision of tourist services is the main cause for which there is fear on the part of deaf people to travel. In SESC / PE Social Tourism agencies (as in any tourism agency) there is a previously established mold when it comes to the elaboration of tourist itineraries and their commercialization, however, the particularities that are linked to the target audience are excluded the tourist segmentation and attractions to be used. In view of the reality found in Brazil, it is observed that there is a need to improve the accessibility of tourist services and equipment. For the hearing impaired, this accessibility occurs through the breaking of the communication barrier that occurs through the use of the Brazilian Sign Language - LIBRAS. By proposing the creation of an inclusive tourist package in this regard, tourism agencies can act in the process of social inclusion of people with disabilities, helping to improve the conditions of access to attractions, and in the progress of the tourism market in this regard. It is extremely important that these types of initiatives are perpetuated, not only by the tourism agencies SESC / PE, but throughout the trade.

Keywords: Social tourism, Accessible tourism, Libras. 


\section{INTRODUÇÃO}

O turismo é uma atividade que possui grande valor social e econômico em diversos âmbitos. Seu desenvolvimento vem ocorrendo de forma estável desde o seu surgimento, porém, como para o resto da sociedade, a questão da acessibilidade ainda aparece como uma necessidade a ser suprida. (LIMA, 2004)

Num contexto histórico, a inclusão de pessoas com qualquer tipo de deficiência sempre foi um aspecto tratado com relutância pela sociedade. Isso resultou, na modernidade, num processo de segregação que parece interminável, haja vista que a inclusão social ocorre de forma lenta e a sociedade sempre acaba por se adaptar de forma incompleta. (ANDRADE; ALVES, 2011) Ainda de acordo com Andrade e Alves (2011), quando se trata do turismo, a situação é similar: os destinos turísticos, principalmente os brasileiros, são extremamente despreparados para receber pessoas com qualquer tipo de deficiência.

Este trabalho tem por objetivo sugerir uma proposta de inclusão de roteiros turísticos acessíveis a pessoas com necessidades específicas nas agências de Turismo Social do SESC/PE, por meio do planejamento de um roteiro acessível a deficientes auditivos para a agência de Turismo Social da unidade do bairro de Santo Amaro em Recife/PE, da seguinte maneira: elaborando por meio do roteiro turístico que sane ou minimize, da melhor forma possível, as problemáticas enfrentadas por pessoas com deficiência auditiva no momento de viagem, promovendo, num âmbito municipal, a apropriação de locais turísticos por pessoas com deficiência auditiva; incentivando, através do roteiro elaborado, a criação de outros roteiros turísticos acessíveis a pessoas com necessidades específicas (não somente a auditiva) na programação anual de excursões promovida pelo Turismo Social do SESC/PE.

Diante disso, ressalta-se o conceito de turismo acessível e a inserção da acessibilidade no turismo (principalmente no segmento do turismo social), que é, segundo Silva (2013, p. 358), "o tipo de turismo que permite a fruição dos espaços, equipamentos e serviços turísticos diversos por parte das pessoas com necessidades específicas, com segurança, autonomia ausência de barreiras". É válido mencionar que a acessibilidade é um fator fundamental na construção de qualquer projeto, visto que ela garante o usufruto dos espaços e dos serviços por todos os integrantes do conjunto social. Geralmente, isso não acontece na prática, o que leva tal fator a se tornar um "diferencial" e uma vantagem competitiva em relação à concorrência, quando deveria ser mostrado como um dos elementos base da vida em sociedade. (BRUNO et al., 2009)

\section{Como iniciativa gênese (no âmbito do Turismo Social do SESC Pernambuco), a}


proposta aqui presente abordará apenas um tipo de deficiência, a fim de facilitar a implantação e incentivar o surgimento de outros projetos similares, além de ter um foco municipal, devido à origem da agência de turismo fomentadora da ideia. $\mathrm{O}$ projeto deu-se devido à observação, ao longo de um estágio extracurricular na agência de Turismo Social da unidade SESC em Santo Amaro - Recife/PE, da inexistência de roteiros acessíveis promovidos pela rede de agências de turismo mencionada.

No Serviço Social do Comércio, a prestação de serviços turísticos ocorre por meio das agências de Turismo Social. Mesmo a instituição abordando a questão da acessibilidade em diversos momentos (principalmente em congressos e palestras), a criação de um roteiro turístico acessível até então não foi uma iniciativa contemplada, apesar do potencial de crescimento social e de bem-estar comunitário. Logo, propõe-se, por meio desse projeto, incentivar a melhora na acessibilidade por meio do turismo, disponibilizando um roteiro acessível a pessoas com deficiência auditiva, abordando destinos em Recife e Olinda - PE, a ser comercializado pelas agências de Turismo Social SESC.

É necessário destacar que o foco do projeto está na construção de um roteiro acessível e suas particularidades, e não em sua execução, que será posterior. Por meio dele, procura-se principalmente estimular que ações similares sejam postas em prática no futuro, de forma a auxiliar no processo de consolidação de uma inclusão social realmente completa. Para demonstrar o processo da elaboração do roteiro mencionado, o projeto foi estruturado, após sua justificativa, com o desenvolvimento a partir dos objetivos, referencial teórico, a descrição dos métodos utilizados para a construção da programação, a explanação sobre a proposta de forma mais aprofundada, e então a conclusão sobre o que foi dado.

A criação de um projeto inclusivo no turismo se mostra relevante por meio dos diversos benefícios que tal iniciativa pode trazer tanto para os organizadores, como para os participantes; e, além de tudo, para a sociedade de modo geral. Incentivar a acessibilidade é incentivar a inclusão social, e a utilização da inclusão social como um vetor na melhora da qualidade de vida e bem-estar comunitário é essencial para a construção de espaços mais salubres e prósperos. (NEVES, NOGUEIRA, OLIVEIRA; 2004)

A questão do bem-estar social está diretamente ligada à missão, aos valores e a visão do Serviço Social do Comércio. A instituição preza pela construção de uma sociedade mais justa e a melhoria da qualidade de vida por meio do desenvolvimento sociocultural, intelectual e sustentável; tais diretrizes compondo o compromisso que o SESC tem com a comunidade pernambucana. (SESC/PE, s.d.) Desse modo, a implantação de um roteiro acessível contribuirá com a difusão dos referidos valores. 
Quando se trata do destino receptor, as vantagens do incentivo à acessibilidade turística estão ligadas à interação direta do turista aos equipamentos, criando um sentimento de pertencimento por parte de indivíduos que não possuem acesso a uma oferta variada de roteiros que proporcionem tal troca de conhecimentos (LIMA, 2004). Por meio da presença do intérprete de LIBRAS é criada a inclusão e a real fruição dos atrativos; com essa quebra da barreira da comunicação, deriva-se a autonomia e a familiaridade. Além disso, destaca-se o incentivo na melhora da acessibilidade dos destinos utilizados.

Um roteiro histórico-cultural, resulta na criação de diversos momentos de educação patrimonial e cultural, que também remete a missão da instituição SESC, e mais especificadamente do Turismo Social. (SESC/PE, s.d.) Para os destinos, há a movimentação de renda (fator inerente do turismo), disseminação da inclusão social, e a utilização dos atrativos como espaços pedagógicos.

Por fim, os benefícios a serem trazidos para o SESC são diversos; haja vista que: a criação de um projeto fortemente ligado a missão da instituição dará incentivo para a melhoria do bem-estar comunitário; impulsionará a promoção de roteiros novos e mais inclusivos para as agências de Turismo Social; contribuirá com a geração de fluxo turístico para os arredores da sede da instituição e para a obtenção de uma maior clientela; agregará valor aos roteiros criados e comercializados pelas agências de Turismo Social; e ofertará incentivo para a melhora do turismo pernambucano de uma forma geral.

A partir disso, sugere-se a proposta de um roteiro acessível em LIBRAS para contribuir com o processo de inclusão social das pessoas com deficiência por meio do turismo, e mais especificadamente por meio do segmento do Turismo Social nas agências de viagem SESC. A junção dessas áreas se fundamenta de forma evidente por meio da fala de Neves (2013, p. 18): “A participação das pessoas com deficiência na atividade turística faz parte do Turismo Social".

Sendo assim, é notável, portanto, a necessidade de criação de projetos que facilitem relação entre essas áreas, levando em consideração o fato de que elas já estão naturalmente interligadas em teoria, mas a falta de ações e propostas de execução se mostra como uma das principais razões da lentidão na melhora da acessibilidade no turismo. Busca-se, então, mudar esse cenário, no âmbito do SESC Pernambuco.

\section{FUNDAMENTAÇÃO TEÓRICA}

Para conceituar o turismo, tem-se a fala de Moesch e Gastal (2007, p. 11), conforme a 
seguir: "É um deslocamento coberto de subjetividade, que possibilita afastamentos concretos e simbólicos do cotidiano, implicando, portanto, novas práticas e novos comportamentos diante da busca do prazer". Ou seja, a atividade engloba muito mais do que apenas o deslocamento geográfico, além de tocar em assuntos como lazer e educação patrimonial. São inúmeros os potenciais da atividade, e, tendo em vista a questão da inclusão social, sua relevância toma ainda mais destaque.

A relação da inclusão social, do turismo e da acessibilidade se dá, indiretamente, pelo segmento turístico chamado de Turismo Social. Segundo Reis e Guimarães (2013 apud Brasil, 2009, p. 9) o Turismo Social é a "forma de conduzir e praticar a atividade turística, promovendo a igualdade de oportunidades, a equidade, a solidariedade e o exercício da cidadania na perspectiva da inclusão". Pode-se relacionar esse conceito ao de turismo acessível, que também aborda a equidade em diversos aspectos.

É perceptivo, entretanto, que o número de iniciativas voltadas para a melhoria do acesso de pessoas com necessidades específicas a atividades básicas como o trabalho, a educação e o lazer vem aumentando principalmente nos últimos vinte anos; e no turismo, o segmento popularmente chamado de Turismo Social possui um papel de grande importância nesse sistema de ações. (NEVES, 2013) De acordo com Silva (2013), o turismo comumente atua de forma a influenciar mudanças, não só econômicas, mas sociais, urbanas e culturais. A atividade turística, quando ocorre, toma para si diversos setores da sociedade; possuindo um caráter multidisciplinar que requer certa adaptação do destino a suas particularidades.

As agências de Turismo Social são a face do turismo do Serviço Social do Comércio. Segundo o site oficial da instituição constante nas "referências" do presente trabalho, o modelo de turismo proposto favorece "novas oportunidades de lazer com baixo custo [...], integração interpessoal, enriquecimento cultural, educacional e histórico e o desenvolvimento integral da saúde". (SESC/PE, s.d., s.p.) É válido mencionar, a partir disso, que o SESC já abordou o assunto da inclusão das pessoas com deficiência no turismo durante palestras como "Ciclo Turismo de Desenvolvimento: Unidade na Diversidade" que ocorreu no estado de São Paulo em 2014 (SESC/SP, 2014) e na Feira de Turismo das Américas, que também ocorreu em São Paulo, em 2013 (ABEOC BRASIL, 2013) mas quando se trata da implantação de roteiros e excursões, as ações ainda são escassas.

Quando se trata da deficiência auditiva, o principal motivo pelo qual há a falta da acessibilidade no turismo é a ausência de intérpretes da LIBRAS nos estabelecimentos, serviços e atrativos turísticos. (ANDRADE; ALVES, 2011) Para que os turistas surdos tenham a mesma experiência daqueles que escutam, é preciso que o mercado turístico ofereça 
profissionais preparados para lidar com esse tipo de comunicação. (RUSCHMANN, 2002) A segmentação do turismo social entra como ator principal no estudo, planejamento e execução de um turismo voltado a abranger as mudanças necessárias na inclusão não só dos surdos, mas também de qualquer pessoa que possua necessidades específicas, consederando que o seu conceito, segundo Reis e Guimarães (2013), é diretamente ligado à criação de ambientes que promovam uma igualdade de oportunidades.

Por tanto a surdez é a "diminuição da capacidade de percepção normal dos sons, sendo considerado surdo o indivíduo cuja audição não é funcional na vida comum”. (SILVA, 2008, p. 5) Visto isso, ainda segundo Silva (2008), a deficiência auditiva abrange não somente aqueles que tiveram perda total de audição, mas também, os parcialmente surdos que podem utilizar ou não de aparelhos de auxílio (próteses auditivas).

Quando se trata do aspecto da inclusão social de pessoas com esse tipo de deficiência, há um precedente histórico impregnado na sociedade, que deixou, como resultante, preconceitos e práticas em relação às PCD a serem perpetuados até a atualidade. Sobre essa parte histórica, Andrade e Alves (2011, p.12) relatam:

\begin{abstract}
No passado, o portador de deficiência auditiva era classificado como alguém incapaz de viver em sociedade. Por este motivo, crianças surdas ou com qualquer outro tipo de necessidade especial eram sacrificadas no ato em que se constatava a deficiência. Quando não eram mortos, eram marginalizados e tinham o direito de educação negado, pois se acreditava que os surdos não estavam aptos a desenvolver qualquer tipo de atividade devido a não ou parcial existência de audição. Porém, com o passar dos tempos, sobretudo a partir da inclusão dos surdos no processo educativo, tornouse claro que este conceito de incapacidade estava incorreto, compreendendo-se que o portador de deficiência auditiva poderia manter comunicação, se fazendo entender entre surdos e ouvintes através de mímica.
\end{abstract}

Então, com o surgimento dos diversos tipos de línguas de sinais, os ruídos de comunicação em relação às pessoas surdas foram sendo diminuídos, mas não completamente extintos. Soares et al. (2013, p. 2) fala que mesmo com diversas iniciativas voltadas para a inclusão de pessoas com deficiência auditiva em ambientes de trabalho, "observa-se uma carência de propostas envolvendo a inclusão do público surdo em projetos de turismo e arte’.

No aspecto do turismo, é dado que as empresas da área muitas vezes não pensam na inclusão dos surdos na atividade (tanto como sujeito ou como consumidor) e não adequam seus serviços de forma a abranger a comunicação necessária para a participação de tais indivíduos nas viagens. Segundo Cintra $(2008$, p. 5) as empresas da área do turismo estão atentas exclusivamente em suprir a critérios de sua clientela atual; as estratégias para os clientes em potencial são fracas; e não estão com atenção às necessidades do turista portador de deficiência auditiva e em seu potencial aquisitivo. 


\section{METODOLOGIA}

Na referida perspectiva, propõe-se uma pesquisa de natureza aplicada, uma vez que se busca gerar conhecimentos dirigidos à solução de problemas específicos; com abordagem quali-quanti, sendo assim classificada, por retratar números numa conjuntura estatística e, por conseguinte, também possibilitar uma análise com maior profundidade contextual.

Possui um enfoque exploratório-descritivo, uma vez que buscará aproximar-se do objeto na perspectiva de levantar as suas características e descrevê-las na tentativa de melhor conhecê-las e contextualizá-las.

A coleta de dados e informações se deu por levantamento documental e de bibliografia. E para a construção do presente relato de experiência se abordou os principais assuntos que compõem o tema acessibilidade, especificamente para pessoas com deficiência auditiva; bem como a logística referente à criação de roteiros/características intrínsecas de um roteiro de turismo. Ademais, houve uma análise de textos sobre as principais problemáticas enfrentadas por esse público no momento da atividade turística.

\section{RESULTADOS E DISCUSSÃO}

Por meio da análise, percebeu-se que o não uso da LIBRAS no provimento de serviços turísticos é a principal causa pela qual há o receio por parte das pessoas surdas em viajar. Lopes (2017 apud STROBEL, 2008, p.28) fala: Os surdos, por vezes, retêm seu desejo de viajar porque a sociedade não está apta a oferecer-lhes um atendimento personalizado em LIBRAS. Muitos não compreendem claramente o que lhes é dito, pois a oralização não é de domínio de todos. Com isso, o processo de comunicação e a experiência da viagem tornam-se prejudicados: sem a compreensão e a comunicação, esse indivíduo com deficiência auditiva poderá aproveitar muito pouco da experiência turística realizada. (LOPES, 2017 apud STROBEL, 2008, p. 28)

Surge-se por tanto, a proposta de um roteiro acessível nesse aspecto, mantendo em mente, a necessidade da inclusão do intérprete de LIBRAS no momento de elaboração do pacote turístico.

Nas agências de Turismo Social do SESC/PE (como em toda agência de turismo) há um molde previamente estabelecido quando se trata da elaboração de roteiros turísticos e sua 
comercialização, excluem-se, entretanto, as particularidades que estão ligadas ao público-alvo concernente a segmentação turística e atrativos a serem utilizados.

A criação do roteiro se dará, inicialmente, pela composição de um orçamento com todos os serviços e atividades a serem incluídas no pacote. (ALMEIDA, JÚNIOR, KOGAN; 2007) Considera-se um dos serviços base para um pacote de turismo o transporte a ser utilizado durante o percurso estabelecido (nesse caso um micro-ônibus), junto com o motorista responsável por tal veículo no momento de passeio (determinado pela empresa de transporte prestadora do serviço). Com o intuito de diminuir ao máximo o custo do pacote e também facilitar a execução do passeio, um dos veículos da própria instituição $\mathrm{SESC/PE}$ poderá ser utilizado podendo ainda, utilizar-se dos recursos humanos internos, sendo uma possibilidade alternativa, a capacitação de colaboradores do setor de turismo social.

É importante ressaltar que foi estabelecido o número base de 25 (vinte e cinto) participantes no roteiro, haja vista que é um projeto piloto que nunca foi oportunamente realizado pelas agências de turismo SESC/PE. As excursões do Turismo Social têm, normalmente, o número mínimo de participantes de 30, e o máximo de 40-45, porém, como o roteiro aqui proposto ainda é inicial, a média de 25 foi escolhida para que não ocorram problemas futuros em sua comercialização. A partir disso, todos os cálculos foram feitos de acordo com os parâmetros usuais.

Outros serviços necessários para a execução do pacote, vem a ser o de Guia de Turismo, que é responsável por acompanhar o grupo em todas as situações durante o passeio, além de tratar dos atrativos de forma esclarecedora e educativa. Segundo Montes (2013 apud CARVALHO, 2003, p. 20), o guia “é o profissional que tem como função acompanhar, orientar, informar o turista, dentre outras atribuições, durante uma viagem a um determinado destino". A partir disso, o guia possui um papel essencial quando se trata da apropriação dos atrativos por parte dos turistas, visto que ele atua como o principal mediador da troca de conhecimentos entre o turista e os diversos componentes do destino.

Entretanto, ele não seria a única fonte de informação operante, considerando a presença de intérpretes da LIBRAS, promovendo-se a quebra de barreira na comunicação entre os participantes deficientes, e o guia de turismo. O guia é o mediador do turista com o atrativo, e o intérprete atuará de forma a intermediar a relação do guia, com o turista, a fim de propiciar uma comunicação realmente completa.

É perceptível de que há uma insuficiência de equipamentos turísticos que promovam um ambiente de comunicação acessível a todos, e isso é algo notável na maioria dos atrativos Pernambucanos: 


\begin{abstract}
A comunidade surda vem sendo negligenciada pelos atrativos, equipamentos e serviços turísticos no que concerne à acessibilidade aos deficientes auditivos em espaços públicos e privados (que se dá por meio da disseminação da Língua Brasileira de Sinais e outras estratégias de comunicação para os surdos), mesmo que tais atrativos turísticos, equipamentos e serviços possuam, de modo geral, potencial para atender a comunidade surda que deseja usufruí-los. (LOPES, 2017, p. 12)
\end{abstract}

Por meio disso tudo, é notável a imprescindibilidade da quebra desse bloqueio comunicativo para que haja uma real participação da comunidade surda no turismo. Com isso, então, inclui-se a diária do guia de turismo juntamente com a de um profissional intérprete de LIBRAS no orçamento do passeio.

Outro fator importante, ora incluso em todas as excursões promovidas pelo SESC Pernambuco, é o seguro viagem. No contrato de prestação de serviços assinado pelo cliente e a unidade do SESC responsável pela organização da excursão, listam-se explicitamente todas as características sobre o pacote: hospedagem que será necessária, transporte, programação, política de cancelamento e reembolso, entre outros, com enfoque no anexo das condições gerais do seguro viagem, que trata de todas as situações de acidente acobertadas pela contratação. É uma característica intrínseca dos pacotes de viagem promovidos pelo SESC, pois a segurança do excursionista é um fator de extrema importância no momento de visitação, incluindo-se também, no orçamento geral do passeio aqui proposto, o valor do seguro viagem.

Quando se trata da programação os ingressos necessários para a visitação de certos atrativos não serão inclusos no orçamento, e nem no pacote. Isso, no intuito da oferta de um serviço com o menor custo possível, de modo a se promover uma iniciativa de turismo acessível no referido aspecto. Já o valor da refeição do dia, entretanto, é incluso, por meio da solicitação de diversos tarifários (para grupos) dos restaurantes nos arredores da execução do roteiro e da contratação direta de tal serviço.

A partir disso, estabelece-se um preço final para a comercialização do pacote turístico, isso com uma base mínima de 25 participantes. O pacote possuirá o seguinte custo para realização:

Tabela 1: Orçamento geral do Projeto

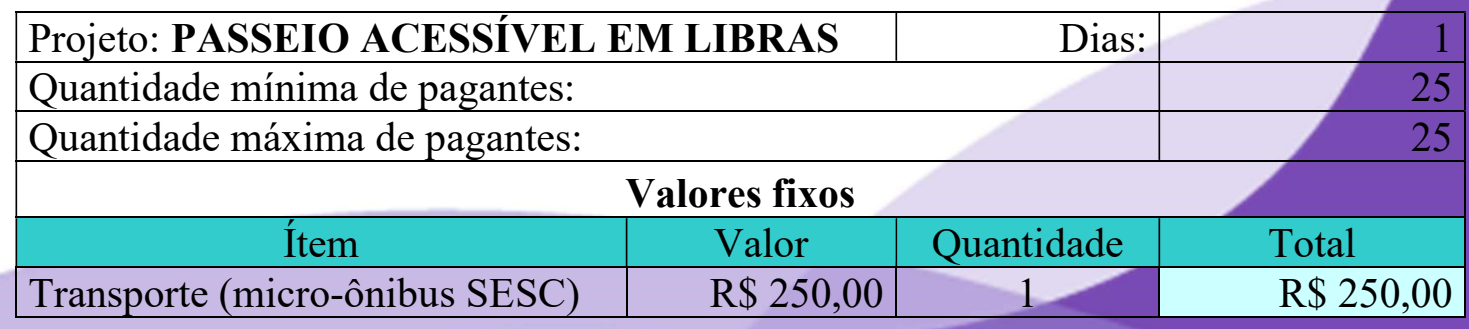




\begin{tabular}{|c|c|c|c|}
\hline Serviço do guia acompanhante & $\mathrm{R} \$ 300,00$ & 1 & $\mathrm{R} \$ 300,00$ \\
\hline Serviço de intérprete de LIBRAS & $\mathrm{R} \$ 400,00$ & 1 & $\mathrm{R} \$ 400,00$ \\
\hline \multicolumn{3}{|l|}{ Subtotal } & RS 950,00 \\
\hline \multicolumn{4}{|c|}{ Valores variáveis } \\
\hline Ítem & Valor & Quantidade & Total \\
\hline Seguro viagem & $\mathrm{R} \$ 2,30$ & 25 & $\mathrm{R} \$ 57,50$ \\
\hline Almoço & $\mathrm{R} \$ 45,00$ & 25 & $\mathrm{R} \$ 1.125,00$ \\
\hline \multicolumn{3}{|c|}{ Subtotal } & R\$ 1.182,50 \\
\hline \multicolumn{3}{|c|}{ Valor total (valores fixos + valores variáveis) } & R\$ 2.132,50 \\
\hline
\end{tabular}

Fonte: Própria (2018).

Conforme a tabela disposta acima, é determinado um valor por pessoa. A partir do tipo de cliente (trabalhador do comércio/dependente do trabalhador do comércio, público participante dos grupos da terceira idade, promovidos pelas unidades SESC/PE e o público em geral), sugere-se uma tabela de preços que priorize a clientela associada, tendo em vista a missão da instituição. Tais padrões são aplicados tanto nos projetos consolidados como nos iniciais. Visto isso, têm-se os valores finais do pacote proposto na tabela 2:

Tabela 2: Valores para comercialização do Pacote

\begin{tabular}{|l|r|}
\hline Valor para comerciários/dependentes & R\$ 98,00 \\
\hline Valor para usuários TSI (grupos da terceira idade SESC) & R\$ 106,00 \\
\hline Valor para o público em geral & R\$ 119,00 \\
\hline
\end{tabular}

Fonte: Própria (2018).

Devido à diminuição do valor do transporte por meio do uso de um veículo da instituição e da escolha de um destino turístico próximo, o custo para o cliente acaba por ser acessível quando se trata do padrão SESC de tarifas (tendo em vista o custo de outros passeios organizados pela unidade de Santo Amaro no ano de 2018). Minimizam-se, então, as barreiras da comunicação, com a presença do intérprete de LIBRAS (o que não impede um indivíduo que não possua deficiência auditiva de participar do roteiro, considerando a presença do guia de turismo acompanhante; mas impulsionando-se a inclusão de pessoas deficientes num grupo previamente inacessível para elas); além de facilitar-se o acesso no âmbito econômico, com as diminuições de custos; dando-se foco no patrimônio histórico municipal, por meio da escolha do destino.

Com o orçamento definido, torna-se necessário se determinar a uma programação a ser seguida, que servirá de base tanto para o guia de turismo, para o intérprete, como também, para a clientela participante.

Conforme mencionado anteriormente, os destinos escolhidos para execução do projeto foram as cidades Pernambucanas de Recife e Olinda, pela proximidade de ambas da agência 
de Turismo Social SESC/PE organizadora do projeto (localizada em Santo Amaro, bairro do Recife), pelo fator da necessidade de melhoria da acessibilidade no turismo nos locais mencionados, pela busca da inclusão social, por meio do incentivo à apropriação dos atrativos por moradores locais que, muitas vezes, não possuem esse tipo de acesso, bem como pelo desejo de criação do sentimento de pertencimento, por meio da visitação.

Por meio da delimitação de todos os gastos necessários para a execução do projeto e dos valores individuais para sua comercialização, propõe-se, então, uma programação a ser seguida no dia do passeio turístico. A programação serve de base para o guia de turismo acompanhante, que é consultado no momento de sua construção, devido a sua experiência em campo.

Devem ser estabelecidos os principais atrativos turísticos a serem visitados, de forma panorâmica ou mais aprofundada, de modo a se assegurar que o passeio ocorra de forma organizada e sistemática. Segundo o Ministério do Turismo, (BRASIL, 2007, p. 13), a finalidade do roteiro turístico está ligada ao "planejamento, gestão, promoção e comercialização turística"; ou melhor, é uma ferramenta relacionada à grande parte das etapas base da prestação de serviços turísticos. O roteiro é uma parte intrínseca do turismo.

Com a essência do projeto sendo o fator da acessibilidade em LIBRAS, há a necessidade da familiarização do intérprete ao roteiro, para que não haja ruídos de comunicação. Promovendo-se a uma participação integrada e contínua de ambos os profissionais (guia e intérprete) na execução do que está proposto. (ANDRADE; ALVES, 2011)

Focando no âmbito da escolha de Recife e Olinda como destinos turísticos, é nítido que ambas as localidades são relativamente consolidadas quando se trata do turismo Pernambucano. Ou seja, os serviços de apoio ao turista são inúmeros e a configuração dos atrativos é mais adequada para a realização de um passeio que não requererá pernoite. Como um dos 65 destinos indutores do desenvolvimento turístico brasileiro, (BRASIL, 2015) Recife possui um papel de destaque quando se trata dos resquícios do nascimento do estado Pernambuco, tendo em vista seu rico patrimônio cultural e histórico. Olinda, como cidadeirmã, tem seu aniversário no mesmo dia que Recife e foi "a segunda cidade brasileira a ser declarada Patrimônio Histórico e Cultural da Humanidade pela UNESCO, em 1982, após Ouro Preto". (BRASIL, 2014, p. 1) Por meio das construções presentes em ambos os destinos, nota-se o potencial da educação patrimonial gerada pela visitação turística.

A excursão terá como o local de saída e de retorno a unidade do SESC em Santo Amaro (bairro do Recife), uma vez que a agência de Turismo Social, organizadora da excursão fica 
localizada no mesmo edifício. São determinados os horários para a reunião do grupo e posterior saída para a execução do passeio, além da ordem da visitação dos atrativos, da pausa para o almoço que estará incluso no pacote, da especificação dos serviços opcionais a serem propostos e do horário de retorno.

Por tudo isso, estabelece-se o seguinte roteiro, que conta com atrativos que possuem destaque no âmbito do turismo histórico, pedagógico e cultural conforme Quadro 1:

Quadro 3: Roteiro do Projeto

07H30 - Chegada ao SESC Santo Amaro;

$08 H 00$ - Saída do SESC Santo Amaro;

Manhã: Olinda

Rua de S. Francisco, Alto da Sé, Ladeira da Misericórdia, Quatro Cantos, Rua Prudente de Morais, Sobrado Mourisco, Praça da Abolição, Sítio de Seu Reis;

$\mathbf{1 2 H 0 0}$ - Almoço em Recife (incluso);

Tarde: Recife Antigo

Praça do Marco Zero, Rua do Bom Jesus, Vivência no Paço do Frevo (R \$ 8,00 entrada inteira, $\mathrm{R} \$ 4,00$ meia)

$16 H 00$ - Retorno ao SESC Santo Amaro.

Fonte: Própria (2018)

Como já mencionado, com o objetivo de diminuir os custos do projeto (a fim de oferecer um pacote acessível também no âmbito econômico), foi retirada a taxa referente à visitação de um dos atrativos. As taxas individuais não possuem preços exorbitantes, de forma que facilita, logisticamente, a entrada do grupo nos estabelecimentos.

Por fim, o passeio ocorrerá em um domingo. A previsão de receita, com base em 25 participantes (10 comerciários/dependentes, 05 usuários do grupo da terceira idade SESC TSI, e 10 usuários/público em geral), configura-se em R $2.700,00$; valor que cobre, de forma completa, os gastos instituídos.

\section{CONSIDERAÇÕES FINAIS}

Diante da realidade encontrada no Brasil, é observado que há uma necessidade na melhora da acessibilidade dos serviços e equipamentos turísticos. Para os deficientes auditivos, essa acessibilidade ocorre por meio da quebra da barreira da comunicação que se dá pelo uso da LIBRAS.

A proposta da criação de mais oportunidades para inclusão social de tais indivíduos no turismo vai de acordo com valores propostos pelo Serviço Social do Comércio, que dissemina princípios voltados para melhora do bem-estar social e qualidade de vida. Por tanto, 
o uso do turismo como vetor para o progresso da acessibilidade se mostra como uma iniciativa exequível e relevante visto os diversificados ganhos (tantos para os organizadores como para os participantes) resultantes da atividade, tanto no âmbito sociocultural, como no econômico e educacional.

Nos destinos escolhidos para a execução do projeto (Recife e Olinda) se nota que muitas das empresas turísticas não se atentam as normas de acessibilidade, o que acaba por criar ambientes repletos de obstáculos para quem possui necessidades específicas. A inserção do profissional de LIBRAS no mercado turístico é essencial para que uma dessas barreiras, a da comunicação, seja quebrada.

Sendo assim, ao propor a criação de um pacote turístico inclusivo nesse aspecto, as agências de turismo podem atuar no processo da inclusão social da pessoa com deficiência, auxiliando na melhora das condições de acesso dos atrativos e no progresso do mercado turístico nesse aspecto. É de extrema importância que esses tipos de iniciativas sejam perpetuados, não só pelas agências de Turismo SESC/PE, mas também, por todo o trade (mercado), tendo em vista a responsabilidade social do turismo e a visão essencial do turista como sujeito ator e não só apenas consumidor (ALMEIDA, 2006); além da utilização do segmento do turismo social como influenciador de mudanças não só no meio turístico, como também por todos os diversos âmbitos que atividade alcança.

\section{REFERÊNCIAS}

ASSOCIAÇÃO BRASILEIRA DE EMPRESAS DE EVENTOS - ABEOC BRASIL. Sistema CNC-Sesc-Senac debate turismo e inclusão na Vila do Saber. 2013. Disponível em: $<$ http://www.abeoc.org.br/2013/09/sistema-cnc-sesc-senac-debate-turismo-e-inclusao-na-vilado-saber/>. Acesso em: 21 de Abril de 2018.

ALMEIDA, Alessandro; JUNIOR, Rinaldo Zaina; KOGAN, Andréa; Elaboração de Roteiros e Pacotes. Curitiba: IESDE Brasil S.A., 2007.

ALMEIDA, Wolney Gomes. Comunidade Surda e o Turismo de Responsabilidade Social: Um Olhar sobre as Diferenças. Caxias do

Sul: UCS, 2006.

ANDRADE, Lívia Leal de; ALVES, Alba Mendonça. A Inclusão do Surdo na Atividade do Turismo Através do Uso de Libras. Salvador: Fundação Visconde de Cairu, 2011

BRASIL. Governo Federal. Recife e Olinda comemoram aniversário nesta quarta (12). 2014. Disponível em: <http://www.brasil.gov.br/editoria/cultura/2014/03/recife-e-olindacomemoram-aniversario-nesta-quarta-12>. Acesso em 18 de Agosto de 2018 
. Ministério do Turismo. Índice de Competitividade do Turismo Nacional. 2015.

Disponível $\quad$ em: $\quad<$ http://www.turismo.gov.br/acesso-a-informacao/63-acoes-eprogramas/4885-indice-de-competitividade-do-turismo-nacional.html $>$. Acesso em $11 \mathrm{de}$ Julho de 2018.

. Ministério do Turismo. Programa de Regionalização do Turismo - Roteiros do Brasil: Roteirização Turística. Brasília, 2007.

BRUNO, Flavio da Silveira; COSTA, Patricia Gomes Ferreira da; LACERDA, Rafael Silva de; TINOCO, Raquel Batista; VALE, Angello Vitoriano do. Investir no diferente para ter um diferencial no mercado. Rio de Janeiro: Rio's International Journal, 2009.

CINTRA, Roberta Rodrigues. O Turismo e a Libras: um estudo sobre a inclusão da Língua Brasileira de Sinais como um dos meios de comunicação no Turismo. Jaboatão dos Guararapes: FMGR, 2008.

LIMA, Renata Porto. Turismo Sem Barreiras: Uma Proposta Para Aumentar a Inclusão dos Deficientes nas Atividades Turísticas. Distrito Federal: UNB, 2004.

LOPES, Kleber Henrique Cavalcanti. Turismo: O surdo e a viagem. Distrito Federal: UNB, 2017.

MOESCH, Marutscka; GASTAL, Susana. Turismo, Políticas Públicas e Cidadania. São Paulo: Aleph, 2007.

MONTES, Valéria Alves. Saberes Profissionais do Guia de Turismo: Passeios Turísticos em Perspectiva Etnográfica. Salvador: UFBA, 2013.

NEVES, Márcia Emilia Rodrigues; NOGUEIRA, Cleonice Lopes; OLIVEIRA, Luciene da Silva. Assistência e Inclusão Social das Pessoas Portadoras de Deficiência: A Complexidade da Questão. Coimbra: Universidade de Coimbra, 2004.

NEVES, Tonderson Ribeiro. Turismo e Acessibilidade: Um Estudo nos Equipamentos Turísticos Natalenses, Aquário Natal e Fortaleza Dos Reis Magos com Base na Associação Brasileira de Normas Técnicas (ABNT). Natal: UFRN, 2013.

REIS, André; GUIMARÃES, Mara Cecília Da Cunha. A Deficiência da Comunicação do Trade Turístico no Uso da Libras. Rio de Janeiro: Editora Arara Azul, 2013.

RUSCHMANN, D. V. M. Turismo no Brasil: análise e tendências. São Paulo: Manole, 2002.

SERVIÇO SOCIAL DO COMÉRCIO SÃO PAULO - SESC/SP. Parâmetros inclusivos de turismo para pessoas com deficiência. 2014. Disponível em: $<\mathrm{http}$ ://centrodepesquisaeformacao.sescsp.org.br/atividade/parametros-inclusivos-de-turismopara-pessoas-com-deficiencia>. Acesso em: 21 de Abril de 2018.

SERVIÇO SOCIAL DO COMÉRCIO PERNAMBUCO - SESC/PE. Sobre o Sesc. Disponível em: <https://www.sescpe.org.br/sobre-o-sesc >. Acesso em: 06 de Julho de 2018 
SILVA, Lucia Palú da. Manual de Orientação de Práticas Interventivas no Contexto Educacional para Professores do Ensino Fundamental. Mandirituba: PDE, 2008.

SILVA, Maxmillian. Acessibilidade em Turismo: A acessibilidade dos surdos aos serviços turísticos de Goiânia-GO. São Paulo: Revista Turismo em Análise, 2013.

SOARES, Maria Helena Alemany; PEREIRA, Janaí De Abreu; PATERNO, Uéslei; VINAS, Abenamar Cristian Elcaras. A Inclusão do Surdo nos Espaços Culturais Turísticos de Florianópolis. Rio de Janeiro: Editora Arara Azul, 2013. 